\title{
LOGISTICS INFORMATION AND COMMUNICATION TECHNOLOGY
}

As technology costs decline and usage becomes easier, logistics managers are managing information electronically at lower logistics expense with increased coordination results in enhanced services by offering better information and services to customers. This article deals with logistics information system, which is to be used in company. Logistics information system (LIS) must have a good structure for every company. LIS characteristics as availability, accuracy, timelines, exception-based LISs, flexibility and appropriate format are described in article.

Keywords: System, logistics, input, output, advantage, disadvantage.

\section{Introduction}

One of the by-products of the computer era is that managers are often faced with more information than can be effectively used for decisions. This abundance of data has several detrimental effects, among which are slower decisions, confused decisions, and the obscuring of important information. Consider, for example, a warehouse manager at a consumer products company receiving weekly reports from corporate management. If unwieldy computer output is delivered, with important and unimportant information mixed, the inexperienced manager will have difficulty finding the data that he or she really needs. More adept managers will find the decision-relevant information but will lose time developing the expertise to do so. Both novice and experienced managers may simply stack the reports in a corner of the office, to read when they have time. Of course, the managers will continue making decisions based on some other source of information and when reading time becomes available much of the formerly relevant information will be obsolete. Giving managers more than they need to know can be very dangerous when it keeps them from effectively receiving and using the information relevant to their current problems. Decisions support systems screen out irrelevant information so it cannot be misused or merely slow down use of the important data [1]. In other words, managers need to have the precise data to deal with the issue at hand without examining a lot of extraneous and irrelevant information [2].

\section{Lis characteristics}

The characteristics that should be concerned with in designing and evaluating LISs are as follows [3].

Availability

The rapid availability of information is absolutely necessary in responding to customers and in improving management decisions. Customers frequently need quick access to inventory and order-location. Many times it calls for decentralized logistics operations so that the information system can access information updated from anywhere.

Accuracy

Logistics information must accurately reflect both current status and periodic activity for customer orders and inventory levels. Accuracy is defined as the degree to which LIS reports match actual physical counts or status. Increased information accuracy reduces inventory requirements.

Timelines

Timelines refer to the delay between the occurrence of an activity and the recognition of that activity in the information system. Timely information reduces uncertainty and identifies problems, thus reducing inventory requirements and increasing decision accuracy.

Exception-based LISs

Sometimes LISs require reviews to be done manually particularly when decisions require judgment on the part of user. The central issue is identifying these exception situations that require management attention and decision making. LISs should be strongly exception oriented and utilized to identify decisions

\footnotetext{
* ${ }^{1}$ Iveta Kubasakova, ${ }^{2}$ Rudolf Kampf, ${ }^{2}$ Ondrej Stopka

${ }^{1}$ Department of Road and Urban Transport, Faculty of Operation and Economics of Transport and Communications, University of Zilina, Slovakia ${ }^{2}$ Institute of Technology and Business in Ceske Budejovice, Czech Republic

E-mail: iveta.kubasakova@fpedas.uniza.sk
} 
that require management attention, particularly for very large orders, products with little or no inventory, delayed shipments, and declining operating productivity.

Flexibility

An LIS must be flexible in meeting the needs of both system users and customers. It must be able to provide data tailored to meet the requirement of a specific customer.

Appropriate format

Logistics reports and screens must contain the right information in the right structure and sequence.

\section{Logistics information and communication technology}

Advances in information systems are transforming the way logistics is managed. Automating the order-processing function leads to better customer services and the storage of more information for later analysis. The growing use of decision-support systems (DSSs) in logistics is helping managers to improve both their decision making and forecasting capabilities (Fig. 1). EDI is another technology that is used for transferring information in an efficient, secure, and lower-cost way than manual systems. Finally, technological advances in various types of hardware will continue to enhance the quality of information available to managers, improve customer service, and lower response times [4].

Nowadays, IT is mentioned as an opportunity to change the structure of logistics system in a firm. IT applications in logistics can be listed as follows:

- Data collection: optical scanning, electronic-pen notepads, voice recognition, and robotics,

- Identification: bas codes, radio frequency (RF) tags and antennas, smart cards and magnetic strips, and vision systems,

- Positional systems (GPS-MPSGIS-Navigator),

- Communication networks and data exchange (EDI-XMLInternet-Satellite-LAN-WAN-EPOS),

- Data storage: data marts and data warehouses,

- Software: DSSs, artificial intelligence, general software, and LIS modules.

\section{LIS structure}

The LIS structure has three main components: input, database and output.

\section{Input}

The input phase is a collection of data sources and data transfer methods and means for making appropriate data available to the computing portion of the system. The LIS data can be obtained from many sources and in many forms, particularly from the following sources.

Customers: customer data are captured during their sales activities, order entries, and deliveries. The obtained data are useful for forecasting, planning and operating decisions. Freight bills, purchase orders and invoices are typical sources for this type of data. The primary source of information in logistics system is sales order because it contains basic data about customer and demanded items. Typical data from the customer locations, their demands, weight, and value of demanded items, date of order and date of shipping, shipment size, packaging, transportation mode, and so on.

Company records: much valuable information can be obtained directly from a company's internal reports, and various operating reports are examples of this type of information source.

Company data are often an untapped source of excellent data. However, such data are neither located at a single point within the company nor are organized in any meaningful way for logistics decision making.

Published data: Professional journals, trade magazine, and government reports are some sources of this type of data. This type of data is more generalized than internally generated data.

Management predictions of future sales level, action of competition, availability of purchased materials are just a few examples of information that are judgemental.

These types of data are maintained in the minds of company personnel, not in company files, computer records, or libraries. Company personnel such as managers, internal consultants and planners and activity specialists are close to data sources and become good sources themselves. Also, clerks who receive customer feedback are valuable sources of such data.

\section{Database management}

The most important component of an information system is the converting module in which data are converted to information and information systems converted to useful knowledge for decision making. Database management contains three main functions: data selection, analysis method selection, and basic data-processing procedure to implement.

The maintenance of data in a database depends on the answers to these four questions:

1. How critical is the information to the decisions the logistician must make in a particular firm?

2. How rapidly does the information need to be retrieved?

3. How frequently is the information to be accessed?

4. How much effort is required to manipulate the information into the form needed?

Because logistical decisions vary in their frequency and in how rapidly required information for them must be made available, storage, retrieval methods should reflect these needs. Generally, the more accessible the information, the more costly the storage and retrieval. Therefore, computer storage and electronic retrieval and display can be justified for the most frequent planning and storage problems. Demand forecasting, inventory control, freight-bill preparation, shipment scheduling, and cost report preparation are just a few of the daily, weekly, or monthly logistics management activities. 
Activities such as warehouse location, facility layout, and material handling equipment review require information at approximately yearly intervals. Computer storage is not usually economical. Most of the information is retained in company files as records.

Finally, infrequent planning and control activities such as private-warehouse construction and private-transportation equipment review usually do not justify maintaining information in a ready form. Rather, information in its raw form can be generated from primary data sources.

The three-tiered or $\mathrm{ABC}$ approach to information-storage requirements is a good approximation method from ranking and identifying how information and data should be stored, if at all This then becomes a basis for deciding what types of storage capacity are needed and how much.

Data retrieval refers to the capacity of recalling data from a database in essentially its raw form or in only slightly modified form.

Data processing is one of the most popular features of the information system. Data-processing activities are relatively simple and straightforward conversations of data in files to more useful forms such as preparing transport bills of lading. Processing data into information is a very basic function of the information system. Data processing usually contains simple operations on data such as sorting and summarizing, coding, and arithmetic manipulations that convert data to useful information for logistics decision making and reporting.

Data analysis is the most sophisticated and newest use made of the information system. The system may contain any number of mathematical and statistical models. Such models provide information that is useful in dealing with some of the most difficult planning and control problems. These models use the database or the output of data- processing steps to find trends and forecast future level of activities and other information that is useful for planning.

\section{Output}

The output of an information system is the interface with the user of system. The outputs in LIS cab are grouped in three types: reports, prepared documents, and results of data analysis from mathematical and statistical models.

1. Reports:

- Summary reports of financial and performance indicators refer to information on which the logistician may take action. They do not in themselves initiate action. Inventory-level reports are of this type.

- Status reports of current activities are special-purpose reports on the date of order receipt and date shipped are examples.

- Exception reports that compare actual performance with goals are special reports that, for example, report on unplanned events such as when transportation costs as a percent of sales a replanted ratio.

- Reports that initiate actions are commands sent out by the LIS to perform some activity. Examples are stock-replenishment orders, trucks-routing schedules, and order-picking list. These reports are based on management rules that are incorporated into the computer-based information system.

2. Prepared documents are common and printable documents such as shipment documents and freight bills.

3. Results of data analysis from mathematical and statistical models for instance, demand forecasting in one of the most useful and important outputs can be obtained from data analysis.

\section{System modules}

This LIS should be comprehensive and capable enough to allow for communication not only between functional areas of a firm (marketing, production, finance, logistics, and so on) but also between members of the supply chain (vendors and customers) [5]. According to Frazelle [6], LIS modules can be listed as follows:

- Customer response system (CRS),

- Inventory management system (IMS),

- Supply management system (SMS),

- Transportation management system (TMS),

- Warehouse management system (WMS).

The CRS and SMS can be seen as parts of the order management system (OMS), and ordinarily WMS contains the IMS module. So LIS has three main modules: OMS, WMS, and TMS.

\section{The order management system}

The OMS is the first point of logistics system contact with customers by managing order receiving and placement. It is frontend system of the LIS. The OMS are closely related to WMS for checking product availability. The customer-ordered items may be available from inventories or may be seen in the production schedules.

This provides information about the location of the product in the supply network, quantity available, and possibly the estimated time for delivery. After checking product availability and accepting the delivery time by the customers, the next step is credit checking. In this step, the OMS communicates with the financial information system to check a customer's credit status. Once the order is accepted, the OMS will allocate the product to the customer order, assign it to a production location, decrement inventory, and prepare and invoice when shipping has been confirmed. 
The OMS does not stand in isolation from the firm's other information systems. If the customer is to be served effectively, the information must be shared.

It should be noted that although the discussion has focused on the orders being received by a firm, there is a similar OMS for the purchase orders placed by the company (sometimes called the SMS). Whereas in customer-based OMS a firm's customer data are important, in a purchase-based OMS the focus is on the company's vendor's data such as their delivery-performance ratings, soft-costs and terms of sale, capabilities, availabilities, an financial strength [5]. The ways customer orders can be placed vary form completely manual to automatic when a customer's computer directly connects to the seller's system without human involvement. There are clear trade-offs in each situation between cost and information quality. In automatic order placement, the speed and accuracy of the process increases. However, initial costs are more than manual orders because of the need for system facilities.

Automating the order-processing function has many advantages for companies. The first one is improving customer services through increases in speed and accuracy. For example, by increasing the speed of the order-placement process, the ordercycle time can be reduced, which means that customers do not need to hold so much safety stocks. In this case, when a customer order is received, the system is able to inform customers immediately about order status, including item availability, shipping dates, and credit availability.
If the order is allocated from inventory, the inventory levels are updated automatically; if the item is not in stock, then, according to production planning, the estimated delivery date is provided to customers. Another benefit to a firm is avoiding human interference in order-handling functions because these activities are now largely computerized. Automation also has financial benefits such as generating customer invoices on the same day as shipments, which accelerates cash flow. Finally, there are fewer billing errors and clerical mistakes [4].

\section{The transportation management system}

The WMS system focuses on a firm's inbound and outbound transportation. Like the WMS, it shares information with other LIS components such as order content, quantity, weight and cube, delivery date, and vendor shipping schedules. The function of TMS as a part of LIS is planning and controlling a firm's inbound and outbound transportation activities. This involves the following:

- Mode selection

- Freight consolidation,

- Routing and scheduling shipments,

- Fleet management

- Maintenance scheduling,

- Vehicle parts control,

- Fleet administration,

- Fleet costing,

- Tachograph analysis,

- Claims processing

The Warehouse Management system:

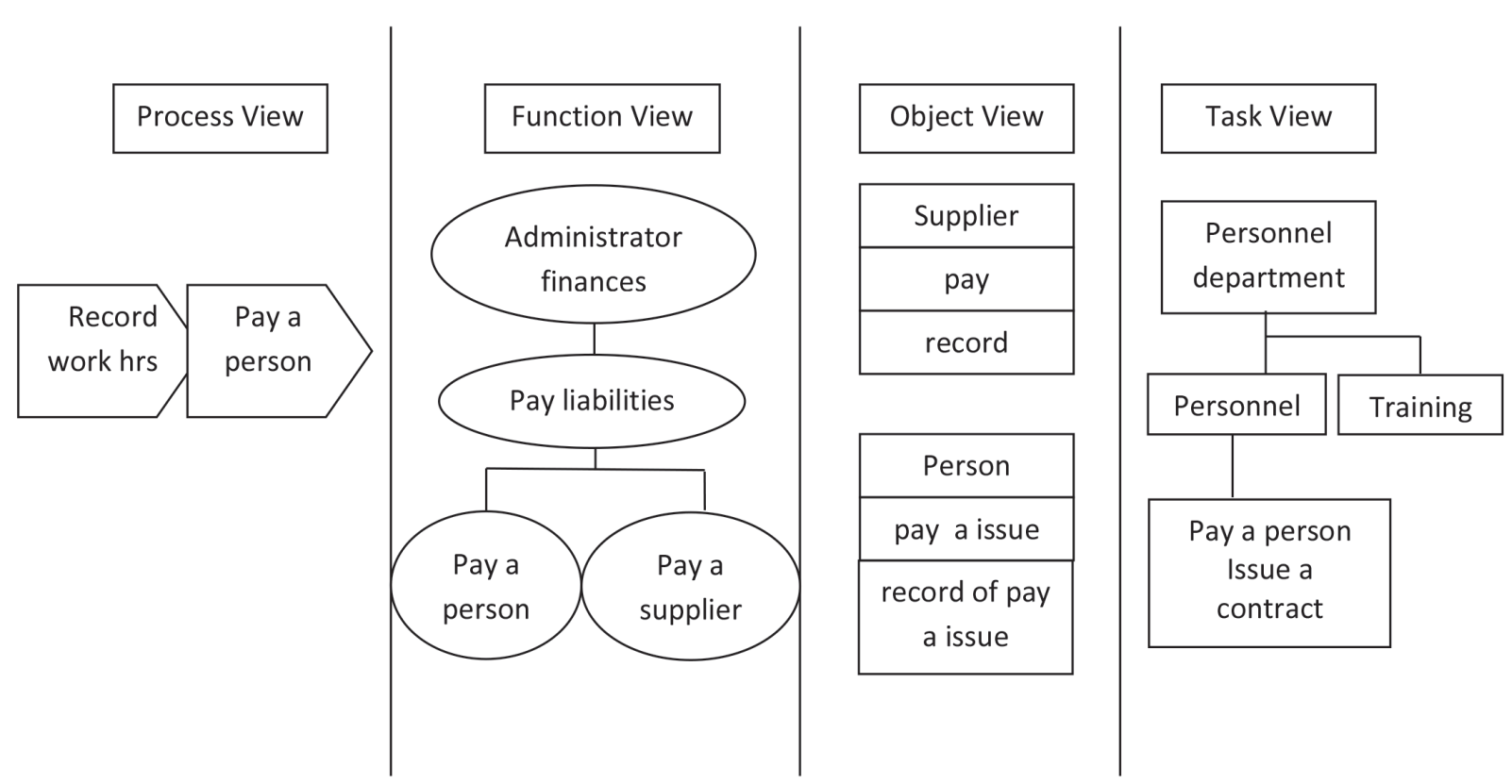

Fig. 1 Four views of information systems for business processes [7] 
- Tracking shipment,

- Freight-bill payment and auditing.

\section{Conclusion}

As important as the order processing system is, it is but one component of the firm's logistics information system (LIS). Indeed, as businesses adopt a more global posture, the need for an LIS is being recognized as an essential ingredient for success in today's marketplace. Unfortunately, managers often find that logistics information can only be obtained by piecing it together from several rather poorly integrated information systems. As logistics channels become longer and more complicated, involving more channel members, efficient coordination becomes the key to effectiveness [8].

The integration of information from varied sources within the firm is a goal that many companies are establishing. Information integration makes available to management multiple bits of information that previously were generated, analysed, and stored in many places throughout the organization. This integrated information source permits managers to examine the operation of the organization in total, rather than in a fragmented, functionally isolated way. In fact, the whole idea behind a decision support system (DSS) is that making data available to managers will enable them to make better decisions. Thus, a logistics decision support system includes appropriate information files from across the logistics function, but, more importantly, it links these through a database system with access to appropriate modelling software [9].

This intent of any LIS is to link all facets of the firm's operation together into a cohesive whole so information flows freely to all of the managers who need it. However, there is also a growing demand for individual company systems to be linked with those of all the partners in a supply chain [10] [11]. Not only must the company's LIS result in more efficient internal operations, but it must also provide customers with better information on order status and shipment location [12] and [13, 14].

\section{Acknowledgements}

This paper presents results of work supported by the Slovak Scientific Grant Agency of the Slovak Republic under the project VEGA No. 1/0331/14.

\section{References}

[1] KENT N. GOURDIN: Global Logistics Management and Competitive Advantage for the $21^{\text {st }}$ Century, Second edition, Blackwell publishing, 2006, ISBN 978-1-4051-2713-4.

[2] KALASOVA, A., KRCHOVA, Z.: Analysis of Road Traffic Accident Rate in the Slovak Republic and Possibilities of its Reduction through Telematics Applications, Transport Systems Telematics: 10 th conference, TST 2010: Katowice - Ustron, 2010: selected papers. - Berlin: Springer - Verlag, 2010. - ISBN 978-3-642-16471-2, pp. 463-468 (Communications in Computer and Information Science, 104, ISSN 1865-0929).

[3] LUCAS D. INTRONA: The Impact of Information Technology on Logistics, Intern. J. of Psychical Distribution \& Logistics Management, 21(5), 1991, pp. 32-37.

[4] eLOGMAR-M Chinese, European Forum one logistics, Shenzhen, P. R. China, 2006.

[5] BALlOU, R.: Business Logistics/Supply Chain Management Planning, Organizing and Controlling the Supply Chain, Pearson Education, New York, 2004.

[7] SINGH, R., AILAWADI, S.: Logistics Management, Prentice Hall of India: New Delhi, 2006.

[8] FRAZELLE, ED: Supply ChainStrategy: The Logistics of Supply Chain Management. McGraw-Hill: New York, 2001.

[9] BARDI, E. J., RAGHUNATHAN, T. S., BAGCHI, PRABIR, K.: Logistics Information Systems: The strategic role for top management. J. of Business Logistics, vol. 15, No. 1, 1994, p.72.

[10] SIMON, M.: America's Systems, J. of Commerce, vol. 5, No. 2, January 12, 2004, p. 117.

[11] BOOKBINDER, J. H., DILTS, D. M.: Logistics Information Systems in a Just in Time Environment, J. of Business Logistics, vol. 10, No. 1, 1989, p. 52.

[12] FARAHANI, R. Z., REZAPOUR, S., KARDAR, L.: Logistics Operations and Management, Elsevier Insights, 2011, ISBN 978-012-385202-1.

[13] SOSEDOVA, J., SUlGAN, M., RIEVAJ, V.: European Transport Corridors and Slovakia, second revised edition, EDIS University of Zilina, 2010, ISBN 978-80-554-0255-0.

[14] LOVECEK, T., RISTVEJ, J., KAMPOVA, K., VACULIK, J., GAMBOA, R., ZAGORECKI, A.: Portal of Security and Safety Engineering as Tool to Increase the Sustainable Development of Higher Education in Security in the European Union and Beyond., Communications - Scientific Letters of the University of Zilina, No. 2, 2013, ISSN 1335- 4205. 